\title{
Color Categories in Language Contact: 'Pygmy' Hunter-Gatherers and Bantu Farmers
}

\author{
NADINE GRIMM \\ Humboldt University Berlin ${ }^{1}$
}

When speakers adopt colors from another language, do they only borrow certain lexical forms or do they absorb whole concepts? And if both a lexical term and a color category are borrowed, are they both borrowed at the same time or is one of them borrowed first? In this paper, I address the question of how color categories are borrowed, providing evidence from Gyeli 'Pygmy' hunter-gatherers (PHGs) in contact with Bantu farmers in southern Cameroon. The data shows rich variability in borrowing patterns. Color categories are not borrowed in toto, but only partially, i.e. the resulting color category in the recipient language only partially coincides with the color category in the donor language. Further, the borrowing of a color category may or may not be in conjunction with the borrowing of a color term from the recipient language. While Gyeli PHGs borrow a lexical term first from neighboring Bantu farmer languages and then expand the color category in a second step, the path of borrowing of Bantu farmers from colonial languages is the inverse. Farmer languages first adopt a new color category, but reject loanwords. Their second step in acquiring a new color is to find a name for the new color category.

\section{Introduction}

Intensive language contact between PHGs and agriculturalists in Central Africa is a well-known phenomenon in the linguistic and anthropological literature (Joiris 2003, Bahuchet in prep.). PHGs remain culturally distinct, despite the tendency to adopt farmers' languages to different degrees. For instance, they maintain a different subsistence strategy and a different social organization. There is little information on what elements PHGs actually adopt when they shift towards farmers' languages because, generally, data on many PHG languages are scarce and language affiliation is often based on lexical comparison.

Color systems are a fertile domain to investigate language contact and borrowing because, beyond assessing which lexical forms for color terms are borrowed, one can also analyze the semantics of the borrowings by observing different color categories and their partition of color space. Much of the extensive literature on color has focussed on the universality of basic color terms and comparing color systems across languages (Berlin \& Kay 1969 on the Basic Color Term theory, Kay et al. 1997 and Cook et al. 2005 with the World Color Survey). Even though stages

\footnotetext{
${ }^{1}$ I wish to thank the Gyeli, Mabi and Bulu speakers, the Volkswagen Foundation/DoBeS initiative, my DoBeS team including Maarten Mous, Emmanuel Ngue Um, Daniel Duke and Christopher Lorenz for helping and supporting me to gather the data which is the basis for this paper. I also thank Asifa Majid, Scott Grimm and the audience at BLS 38 for helpful comments and advice.
} 


\section{Nadine Grimm}

in cross-linguistic color evolution are an important part of these studies, less attention has been paid to the processes in particular languages of innovations and changes in color categories. Nor has the role of language contact been systematically examined. Both aspects are addressed in this study. In the following, I will outline the complex language situation and describe my methodology. In sections 2 and 3, I compare the paths of color borrowing between Gyeli PHGs and Bantu farmers and between Bantu farmer and colonial languages, respectively. This includes an analysis of the partition of color space in different speech communities as well as different effects a phase of transition has on the partition of color space.

\subsection{The Language Contact Situation}

Like most of west Africa, the south of Cameroon presents a highly complex language situation. Many indigenous languages in a small geographical area, multilingualism, and the use of colonial languages such as French and English contribute to a multitude of language contact situations with multiple layers and directions of borrowing.

(1) Map of the Gyeli area and its neighboring Bantu farmer languages (based on UN map of Cameroon, no. 4227)

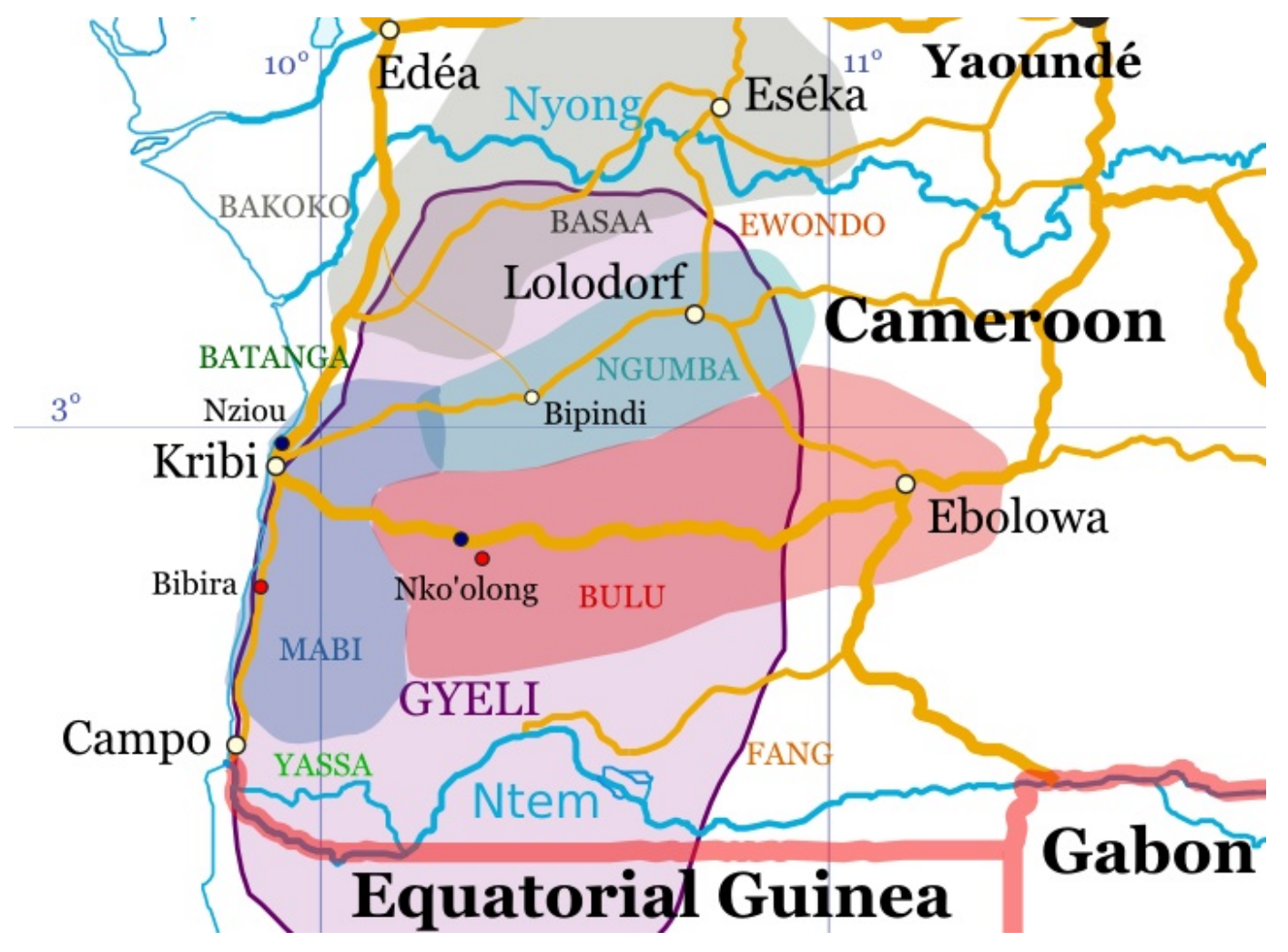

For the analysis on color borrowing, I collected data from four speech communities: two Gyeli PHGs varieties and two neighboring farmer languages, Mabi and Bulu. 


\section{Color Categories in Language Contact}

The Gyeli PHG varieties are represented by red dots and the farmer languages in this study by blue dots on the map shown in (1). ${ }^{2}$ One Gyeli variety is in contact with Mabi (coastal Kwasio dialect), which I will refer to by its village name 'Bibira.' The other Gyeli variety is spoken in the inland village Nko'olong which is in contact with Bulu speakers. Data on farming communities come from these two contact languages. Mabi data was collected in Nziou, a village belonging to the Kribi district while Bulu color data was collected in the farmer village closest to Nko'olong which has the same name. ${ }^{3}$ I will start out by describing Gyeli and then move on to the Bantu farmers' languages.

Gyeli, also called Kola in the north, is a Bantu A80 language spoken by about 4000-5000 PHGs known as Bagyeli (or Bakola). Speakers live in small communities averaging 20-30 Bagyeli in a settlement. These settlements are dispersed over an area of approximately $4800 \mathrm{sq} \mathrm{mi}\left(12.500 \mathrm{~km}^{2}\right)$ of mainly tropical rainforest. In this territory, eight other Bantu languages are spoken by farming communities. The Bagyeli are currently shifting from their traditional way of life to sedentary farming due to massive ongoing changes in the environment which ultimately make animals disappear that the hunter-gatherers depend on. In the course of adopting a new subsistence strategy, the PHGs also shift to the languages of their farming Bantu neighbors. Depending on which other Bantu language they are in contact with, different Gyeli dialects have evolved. For instance, Bagyeli who are in contact with Bulu communities speak a different variety than Gyeli speakers in contact with Mabi. Generally, language contact is intense between PHGs and neighboring Bantu farmers, as has been shown for other PHG groups in central Africa (Thomas 1976:28, Lewis 2002:18, Vorbichler 1960:87). Due to prestige and social pressure, PHGs borrow from and shift to farmers' languages, not the other way around.

Neighboring farmer groups consist exclusively of Bantu A speakers: Batanga and Yassa of the A30 group, Basaa and Bakoko of A40, Ewondo, Bulu, and Fang of A70. Kwasio is another A80 language and the closest relative to Gyeli. Languages of the farmers are generally more prestigious and therefore used in communication with Gyeli speakers who are shifting to (some of) the neighboring farmers languages. Language shift is gradual and differs across various Gyeli PHG groups and various neighboring farmers, depending on the nature of contact. For instance, the Bagyeli have a less close contact to the Yassa who are traditional deep sea fishermen (Daniel Duke, p.c.) and therefore have less of an interest in foraging produce. In contrast, contact between the Bagyeli and the Mabi, the Ngumba, the Bulu, and the Basaa is much closer.

In addition to the Gyeli and farmers languages, a third layer of complexity is the colonial language French spoken in the area. French is still the language of the elite used in education, administration, politics, and institutions. Farming populations

\footnotetext{
${ }^{2}$ Note that language area extensions and the location of places are approximations.

${ }^{3}$ The Bulu of Nko' olong consider the PHG settlement as belonging to their village; however, the Bagyeli are spatially separated by about a mile.
} 


\section{Nadine Grimm}

study French at school and master it to varying degrees, depending on the level of education. Generally, the Bagyeli's neighbors have some command of French, which varies from basic to good and which they use in inter-ethnic communication if the interlocutors do not speak the same Cameroonian languages. In contrast, the Bagyeli do not speak French since very few of them, even among their children, have gone or are going to school, so they do not learn French. In communication with Bantu farmers, they usually use the farmers' language.

In terms of language contact, two color ${ }^{4}$ borrowing scenarios arise as illustrated in (2). On the one hand, Gyeli PHGs borrow color terms, and eventually the color categories that go with the terms, from their farming Bantu neighbors. Farmer languages, on the other hand, borrow color categories from colonial languages, i.e. mainly French. I will explore the two scenarios in turn in sections 2 and 3.

(2) Two scenarios of borrowing situation

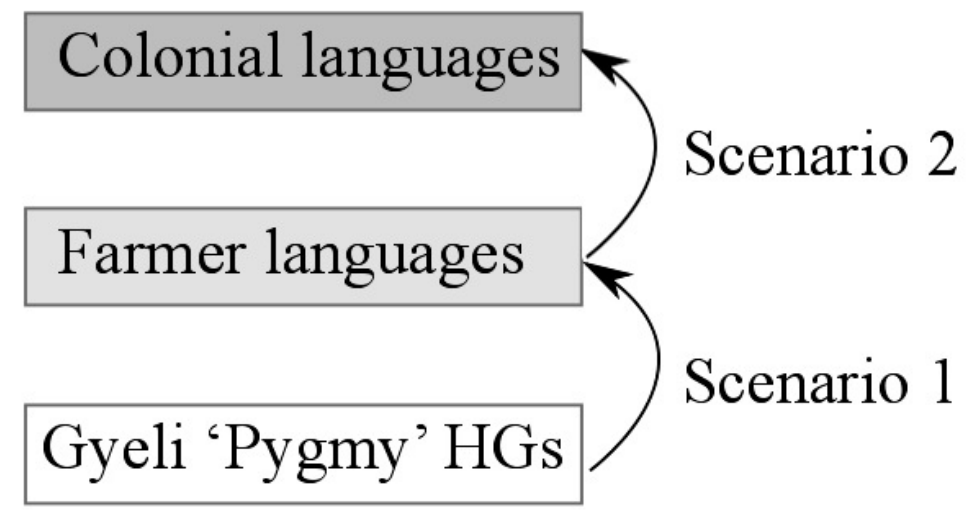

\subsection{Methodology}

I established basic color terms and the partition of color space in each of the four languages through elicitations with color chips and interviews. These data were then compared within the single communities as well as across communities (PHG-PHG, PHG-farmers, farmers-farmers). One way to understand the semantics of a color term in a speech community is to analyze the partition of color space and thereby the extension of single color categories in the space. (3) shows a chart of language-neutral color space composed of eighty color points, known as 'hues.' The chart shows how hues occur naturally and is not based on color naming in a particular language. Different languages and speech communities may divide up the space in this chart in different ways, depending on the kind, number, and extension of color categories existing in the language. For instance, one language may call a hue pink while for another language, the same hue falls into the category of red because that language either does not have the category pink or the pink and

\footnotetext{
${ }^{4}$ I consider 'color' here as a cover term including both color term and color category.
} 


\section{Color Categories in Language Contact}

red categories receive different extensions.

(3) Color space chart

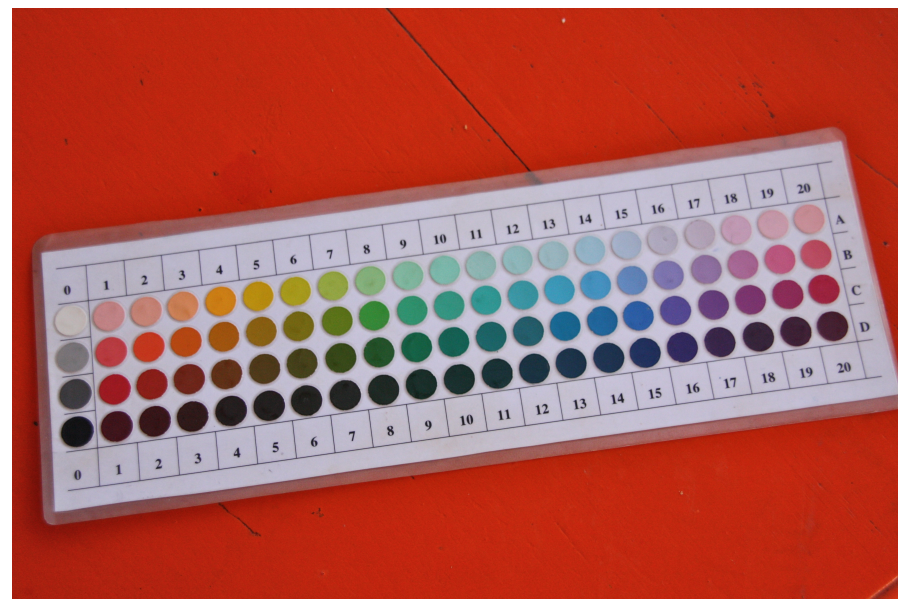

In order to establish the partition of color space for a particular speech community, basic color terms were elicited from individual speakers and in groups. In a second step, informants were interviewed one-by-one so that they could not influence the answers of others. In each community, at least twelve speakers were interviewed. Each informant was tested for color blindness. Then, consultants had to name each color in a booklet provided by the Max-Planck Institute of Psycholinguistics in Nijmegen (Majid \& Levinson 2007), containing the eighty color chips shown in (3). In the booklet, the hues are, however, presented in a fixed random order. They are standardized Munsell colors and sampled twenty equally spaced hues at four degrees of brightness all at maximum saturation (Majid \& Levinson 2007:23). Then I plotted the most frequently given term for every hue in a speech community onto the color space chart. This provided an average partition of color space for a speech community.

\section{Scenario 1: Gyeli PHGs Borrow From Bantu Farmers}

Gyeli PHGs have borrowed two colors from Bantu farmers, namely yellow and green. The path of borrowing is that the lexical form is adopted first. After acquiring the term, the corresponding concept, i.e. the extension of the color category in color space, is approximated, a process that has not been completed yet. In other words, the Gyeli PHGs have for instance adopted the word 'yellow', although there is some disagreement between Gyeli PHGs and their farming neighbors as to which hues qualify as instances of yellow.

Historically, Gyeli as well as the surrounding Bantu farmer languages disposed of only three color categories, namely black, red and white. ${ }^{5}$ More recently acquired colors include first yellow and then green, an order which is predicted by

${ }^{5}$ Gyeli and Mabi have three different color terms for the white category, a scenario which is actually contrary to the predictions of the Basic Color Term theory. ná mbàmbàlà is the default term for 


\section{Nadine Grimm}

the Basic Color Term theory (Berlin \& Kay 1999). Gyeli and Mabi use the same color terms for both traditional and newly acquired color expressions. The original basic color terms in Bulu differ significantly from those in the other two languages which indicates that no borrowing and/or areal spread seems to have taken place. The recently innovated color terms are, however, cognates in the three languages.

(4) Color terms for different color categories

\begin{tabular}{|lll|}
\hline Gyeli and Mabi & Bulu & \\
\hline ná vyû̀ & évìndì & 'black' \\
ná bì & évèlè & 'red' \\
ná mbàmbàlà & éfùmùlù & 'white' \\
\hline mpúlı̀ & mfóò & 'yellow' \\
máká & bìkáá bìlók & 'green' \\
\hline
\end{tabular}

All of the languages under consideration show differences in the morphosyntactic properties of original basic color terms in contrast to the innovative color terms, as shown in (4). Also, traditional color terms display different morphosyntactic properties across languages. In Gyeli and Mabi, the original color terms seem to form a part of speech on their own. They may have originally been derived from verbs, but synchronically they do not take any subject agreement marker like verbs in these languages do. Instead, they are all preceded by a particle ná. Also, in contrast to newly innovated color terms, they can be reduplicated - ná vyûvyû, ná bìbì, and mbàmbàlàmbàmbàlà. ${ }^{6}$ In comparison to Gyeli and Mabi, in Bulu, the original three basic color terms do not form a part of speech on their own, but are nouns belonging to noun class 7 . According to Bates (1904), they are derived from the verbs vé 'be/get red', vìn 'be/get black', and fùm 'be white'.

Recently acquired color terms are nouns in all three languages. They display a typical Bantu noun structure including noun class prefixes. In Gyeli and Mabi, mpúlè 'yellow' is used in the singular class 3 of gender 3/4 while má-ká 'green' takes the plural noun class prefix mà- of class 6 of gender 5/6. Recently adopted color terms in Bulu do not belong to noun class 7, unlike Bulu traditional color terms: mfóò yellow' is in noun class 3 and bikáá bilók 'green' in noun class 8 . Further, these color terms are not derived from verbs, unlike traditional color terms.

In terms of their meaning, recently innovated color terms not only designate a color, but refer originally to an object in the world of plants. mpúlè in Gyeli and Mabi and its cognate mfóò in Bulu designate, besides the color yellow, a kind

white. The other two white terms, ná yê and ná pfû, seem to implicate a change of color, but their semantics still need further investigation. Since these terms for white almost exclusively show up in individual use, but not in an average picture of the speech communities, the other two white terms will not be considered further at this point. Bulu does not have any additional color terms for either of the categories.

${ }^{6}$ The meaning contrast of the reduplicated forms is at this point unclear to me. 


\section{Color Categories in Language Contact}

of tree, enantia chlorantha, which is known under the trade name African yellow wood. The primary meaning of má-ká is 'leaves'. In Bulu, it is the same word, bìkáá, just in a different noun class. Also, the color green in Bulu is not only expressed by 'leaves,' but by a juxtaposition of bì-káá bì-lók, meaning 'leaves grass.'

Looking at the way newly innovated color terms have spread in the area, I will show that recent color innovations were established earlier in Bantu farmer languages and that Gyeli PHGs borrowed the color terms for yellow and green from Mabi. This holds for all Gyeli PHG varieties; even in Nko'olong, which is in primary contact with Bulu, the Bagyeli use the Mabi borrowings and not borrowings from Bulu. The path of borrowing from Mabi into Gyeli is as follows. First, the use of a lexeme which actually already exists in the languages of the area, is borrowed. Both, mpúlè and máká, are already part of the Gyeli lexicon designating a type of tree and leaves respectively. The crucial thing which is borrowed is their use as a color term. In a second step, the associated color category is expanded according to the model of the donor language's category extension in the color space. Evidence that the recently adopted colors developed earlier in Bantu farmer languages than in the Gyeli PHG varieties who borrowed the colors from their farming neighbors comes from both historical records of Bulu as well as from the partition of color space in the single communities. Each of these will be discussed in turn.

\subsection{The Case of mpúlè 'Yellow'}

The color category yellow is a recent innovation in Mabi and Bulu, and even more recent in Gyeli varieties. The Bulu literature provides information on how the name of a particular tree developed a second meaning, namely that of a color. Initially, yellow in Bulu was used in a compound as a specification of red: évèlè mfóò (Bates 1904:145) meaning a specific type of red, namely the 'red of the mfóo tree'. Eventually, évèlè 'red' was omitted from the compound, while, at the same time, yellow split off from the red color category and became a category on its own.

Currently, speakers are not aware of the connection between the tree and the color anymore. When asked whether mpúlè has another meaning than yellow, the usual answer is that it only designates the color. When explicitly asked about the connection between the tree and the color term, many speakers think that the tree was named after the color, even though the historical records in Bulu indicate that it was the other way around.

mpúlè in Mabi and Gyeli shows signs of being grammaticalized. Some speakers have started using the marker ná with mpúlè, which usually is only used with the traditional, non-nominal color terms in these languages. The ongoing grammaticalization and adoption of traditional color term morphology shows that traditional color terms serve as role models of 'real' color terms. Treating newly innovated color terms grammatically like traditional color terms further indicates that the new color is firmly established as a category on its own.

In comparison, green is an even more recent innovation and not being grammaticalized. Speakers are aware of the lexical source - leaves - that provides the color 


\section{Nadine Grimm}

with a term and of using a kind of comparison. For instance, some explain that the color of leaves is black, but if someone is wearing a green shirt, one would say that the shirt has the 'color of leaves', nsínó wá máká.

\subsection{Partition of Color Space in Gyeli PHG Varieties}

Comparing the partitions of color space in the various speech communities reveals significant differences across languages and even across varieties of the same language. The extension of the recently acquired colors yellow and green in the Gyeli PHG variety in Bibira is less expanded than in Nko'olong. At the same time, new color categories in both Gyeli varieties are not yet as expanded in the color space as in Bantu farmer languages from which Gyeli borrowed the color terms. The differences in the extension of color categories can be interpreted as representing different stages in the establishment of new colors.

Data on the Gyeli variety spoken in Bibira, illustrated in (5), which is in contact with the Mabi farmer language, shows that the extension of the white category is significantly larger than in the Gyeli variety in Nko'olong, (6), which is spoken in the Bulu contact area. At the same time, newly acquired colors such as yellow and green in Bibira do not have a large extension in the color space, compared to traditional color categories. In contrast, both categories take up relatively more space in the Gyeli partition of color space in Nko'olong.

(5) Partition of color space in Bibira, the Mabi contact area

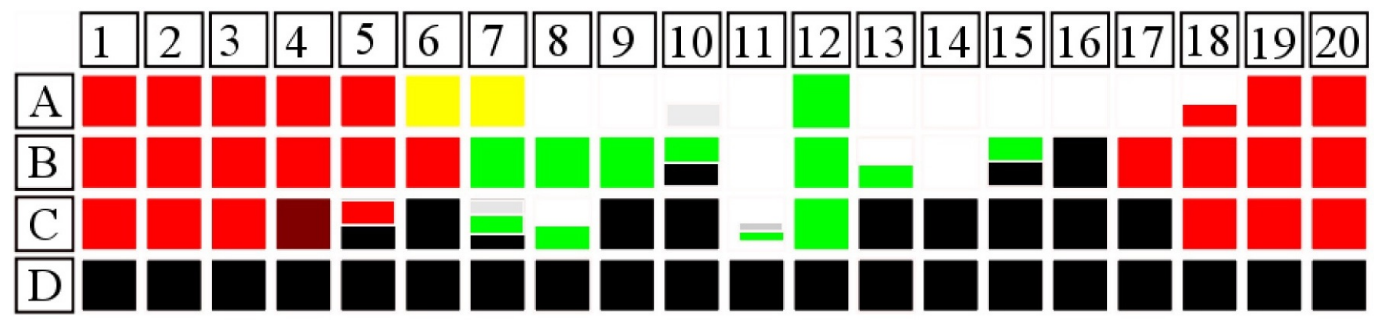

(6) Partition of color space in Nko'olong, the Bulu contact area

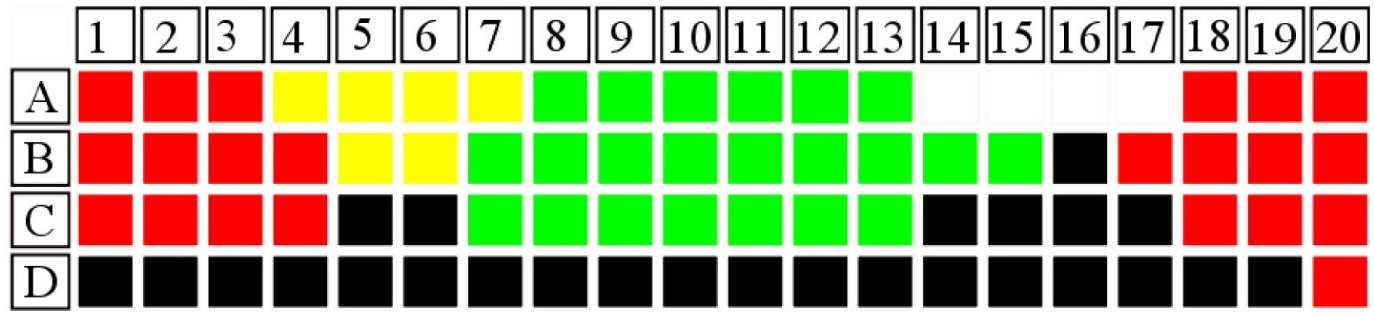

In contrast to farmer languages, Gyeli PHG varieties generally show a larger extension of traditional and a smaller extension of newly innovated color categories, comparing Gyeli in Bibira (5) with Mabi (8), and Gyeli in Nko'olong (6) with Bulu 


\section{Color Categories in Language Contact}

(9). At the same time, newly innovated color categories generally have a smaller extension than in their farmer contact counterpart. Thus, both the yellow and the green space are much smaller among the Bibira PHGs than among the Mabi farmers. The same is true for the the Gyeli PHGs in Nko'olong where yellow and green have a smaller extension than among the Bulu farmers.

The partitions of color space in the farmer communities reflect a more evolved stage in color acquisition in comparison to the Gyeli PHGs. From the perspective of the Basic Color Term theory, languages add new color categories to their inventory in a predictable fashion (rather than losing them). Since farmer languages have more color categories than the Gyeli PHGs, as will be discussed in the next section, their color systems are at a later stage in the color evolution trajectory than those of the Gyeli PHGs. At the same time, there are also differences among the farmer languages. The Mabi color system is more conservative than the Bulu one since it has fewer color categories.

Also the two Gyeli PHG varieties are at different stages in the color acquisition trajectory. The Gyeli PHG variety in contact with Mabi is more conservative than the variety in contact with Bulu. Given the language contact situation where PHGs borrow from farmers (and not the other way around), it can be assumed that Gyeli PHGs orient themselves towards the farmer's color systems when establishing the extension of a color category. Therefore, the Gyeli PHG varieties reflect the differences in the color evolution trajectory of their respective contact farmer groups, as illustrated in (7).

(7) Color evolution trajectory in Gyeli PHG and farmer groups

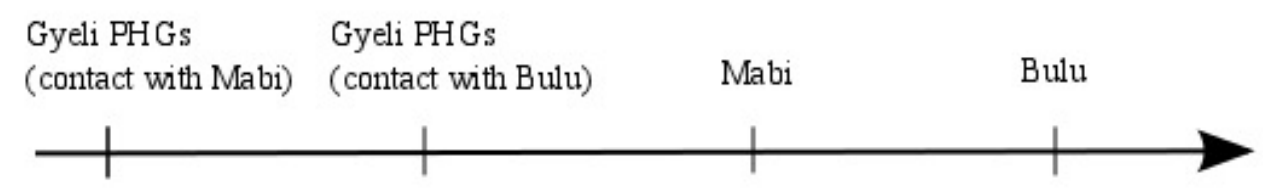

The stability and conventionalization of a color category can be understood by examining the properties of the category boundaries. Well-defined category boundaries suggest that a category has stabilized, i.e. the speech community agrees upon its extension. Fuzzy boundaries indicate the opposite, namely that the category is not yet fully established, but still subject to transformation. Following this argumentation, the more conservative system in Bibira is not only reflected in its category extension, but also in its category boundaries which are less well-defined and clear cut than in the Gyeli variety in Nko'olong, (6). Especially the categories white and green do not represent contiguous areas as would be expected by Roberson et al. (2000:395) who claim that 'no language would exhibit categories that include two areas of color space but excludes an area between them.' Instead, a green strip divides the white category in two, one part stretching from 8 on the scale to 11 , being interrupted at 12, and the other part stretching from 13 to 18. Also, the green 


\section{Nadine Grimm}

category encloses little pockets of white as in C8. In contrast, color boundaries in Nko'olong are clearer and better defined. This indicates that color categories and their boundaries in Nko'olong are well established and conventionalized. Even the newly innovated ones, have become stable (for the moment) and speakers agree, on average, about the semantics, i.e. the extension, of single color categories. For Bibira, however, the interpretation would be that category boundaries have not been fully stabilized yet. Speakers are still in the process of conventionalizing how they call certain hues and what the extension of a certain color category is. This can also be seen in boundary areas such as $\mathrm{C} 7$ or $\mathrm{C} 11$. For these color chips, no majority answer was obtained, but three different answers covering a third of the interviewed consultants each. For instance, for $\mathrm{C} 7$, one third of the consultants labelled the color black, one third called it green and the last third called it white. ${ }^{7}$ Differences in category boundaries in the farmer languages will be addressed in section 3 .

As an interim summary, I conclude that the two Gyeli varieties represent different stages in the acquisition of new colors in a language. Both use the same lexemes for yellow and green as their farming neighbors, but the color categories are not yet as expanded in the color space as in their respective contact languages. At the same time, their expansion also differs inter-dialectally, the variety in Bibira being more conservative than the one in Nko'olong. The more conservative color space partition is characterized by a smaller expansion of recently innovated colors as well as a lesser degree of conventionalization and stabilization displayed in less well-defined category boundaries.

\section{Scenario 2: Bantu Farmers Borrow from Colonial Languages}

Ongoing innovation and acquisition of new colors in farmer languages stem from contact with colonial languages, particularly French, but to some degree also English. In contrast to color borrowing in Gyeli PHG varieties, farmer languages first adopt a new color category, but do not borrow the color term that goes with the category in the colonial language. For instance, Bulu speakers are aware that there is a blue category which is distinct from green or any other category, but at the same time, speakers do not have any conventionalized term for the new category. Both the Mabi and the Bulu seem to refuse the use of loanwords which they only used when pressured to give a hue a name. So, the second step in color borrowing in farmer languages is to find a vernacular name for the newly acquired color category.

Most Bulu and Mabi speakers are fluent in French since they received schooling in French for several years, unlike the Gyeli PHGs who usually do not go to school or, if they do, for not as long nor as regularly. The French education system seems to have a direct impact on farmers' color systems. This was apparent in the much longer reaction times farmer consultants had when asked for the name of the color

\footnotetext{
${ }^{7}$ What is special here about the white term is that in these boundary areas speakers sometimes do not use the default white term, but one of the more unconventional ones, namely nà yê which also has the meaning of bleached out. The other atypical white term, nà pfû, does not show up at all in the average picture of a speech community, but consistently in individual speakers.
} 


\section{Color Categories in Language Contact}

chips in their own languages, even though one would expect that they are more used to such interrogation tasks than community members who have not received any school education. When running the same naming task with Mabi and Bulu speakers, but asking for the color names in French, reaction times were, however, much shorter. Also, the answers for the French naming showed results nearly as one would expect them for French speakers. It seems, then, that two color systems are coexisting in speakers of farmer languages: a local and a colonial color system. At the same time, the colonial color system appears to greatly interfere with the local color systems. Speakers often gave answers such as, "I know that color, but we don't have a name for it in our language. In French, it would be violet."

\subsection{Partition Of Color Space In Farmer Languages}

The partition of color space in the farmer languages Mabi and Bulu is characterized by the emergence of new color categories which trigger major changes in the extension of previously existing color categories. The partitions of color space of the two farmer languages are not identical, but differ in (i) the number and type of color categories, (ii) the extension of color categories, and (iii) their boundaries. Category boundaries will be discussed in the following subsection. Mabi has a more conservative color system than Bulu, just like the Gyeli variety in contact with Mabi is more conservative than the Gyeli variety in the Bulu area.

Mabi (8) has so far only developed an orange category. The emerging blue area in B12 does not fully count since, as indicated in the figure, only half of the informants called this hue blue while the other half would classify it as green. In this sense, the development of the Mabi color system goes against the predictions of the Basic Color Term theory which claims that blue should be the next category that is acquired after green (Berlin \& Kay 1999). In comparison, Bulu (9) has already acquired more color categories including blue and purple. As with blue in Mabi, the orange category does show up in B3, but does not receive any majority answer. The Bulu color system and its development follow better the predictions by the Basic Color Term theory than Mabi does.

(8) Partition of color space among the Mabi in Kribi

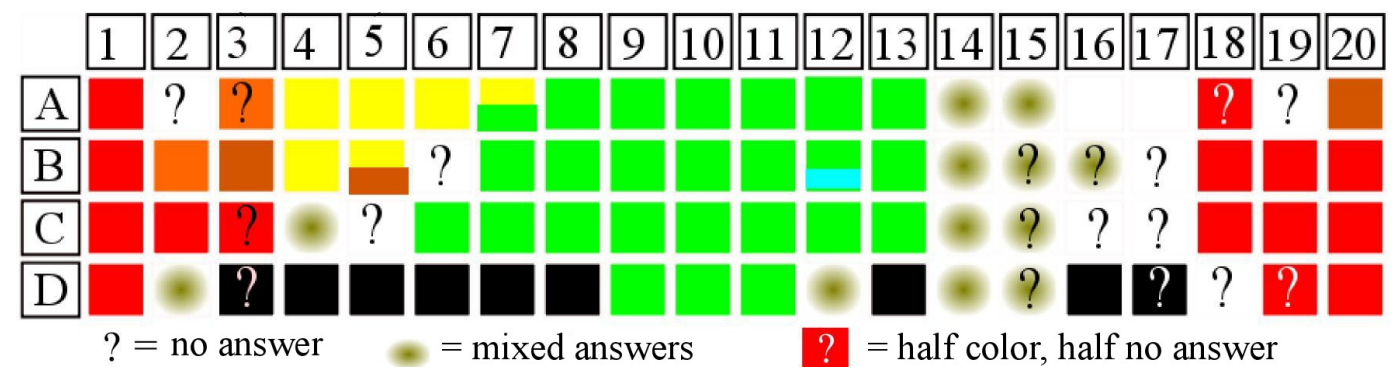

For both farmer languages, the space of the original three color categories black, red, and white has shrunk due to the emergence of other color categories which are 


\section{Nadine Grimm}

(9) Partition of color space among the Bulu in Nko'olong

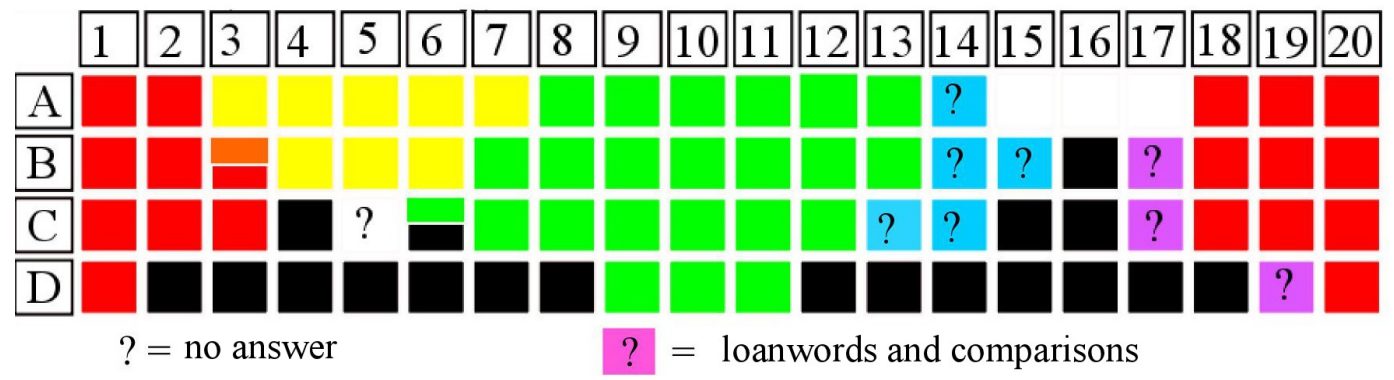

taking up the space. When comparing the partition of color space of farmer languages with their Gyeli PHG neighbors, the extension of the traditional color categories is much larger in the PHG varieties, which represents a more conservative system than in the farmer languages. As to the next wave of color innovation containing yellow and green, which are just entering the Gyeli PHG varieties now, these categories seem to have had reached a certain degree of stability before yet other colors such as blue or orange started emerging. They seem to be almost identical in the two farmer languages; differences in the extension and boundaries are only due to yet other new color categories such as orange which is taking up some of the yellow space in Mabi and blue which is taking up some of the green space in Bulu. Interestingly, the green category still has the largest extension of all categories in both farmer languages. Both languages also have in common that the latest color innovations, blue, purple, and orange, have a comparatively small extension in the color space.

\subsection{Characteristics Of Transition Phase}

The data on Gyeli PHGs and Bantu farmers suggest that the entrance of a new color category into a language is accompanied by a phase of transition. New categories expand and take up part of the space of previously existing categories. New category boundaries need to be defined. In a phase of transition, both the extension and the boundaries have not conventionalized and stabilized yet. The effects this phase of instability and transformation have on the partition of color space are, however, different in different speech communities and seem to correlate with the way a new category enters the system. In the Gyeli PHG varieties where a term is borrowed first before expanding the new color, category boundaries appear quite neat, even in the phase of transition, thus the only effect is that new categories have not yet reached their final extension. This is especially exemplified by the variety spoken in Nko'olong (6) which does not show any fuzzy boundaries. Effects of a transition phase are clearer in the Bibira variety (5) with some discontiguous white and green areas and a lack of majority answers for a few hues.

In contrast, farmer languages acquire a new color category first and then conventionalize a term for the new category. They show the same transition effects 


\section{Color Categories in Language Contact}

than the Gyeli PHGs in Bibira (discontiguous areas, no majority answer), but to a greater degree while also displaying other effects. Their transitory partition of color space and category boundaries appear less clear and well-defined than in the Gyeli PHGs. This impression of fuzzy category boundaries is caused by some characteristics of transitory effects that both farmer languages share, but that do not overlap entirely in both languages. Unconventionalized areas in the farmers' color space are generally marked by (i) discontiguous areas, (ii) a lack of majority answers, (iii) loanwords, and (iv) gaps. (10) shows, however, that not all of these characteristics occur in both farmer languages. For instance, loanwords are absent in Mabi, but used in Bulu. A cross in the table represents the absence of a feature while a tick represents its presence.

(10) Presence or absence of different transition effects in the color space

\begin{tabular}{|l|ll|ll|}
\hline & Gyeli PHGs & Bantu farmers \\
& Nko'olong & Bibira & Mabi & Bulu \\
\hline discontiguous areas & $x$ & $\checkmark$ & $\checkmark$ & $\checkmark$ \\
lack of majority answer & $x$ & $\checkmark$ & $\checkmark$ & $x$ \\
loanwords & $x$ & $x$ & $x$ & $\checkmark$ \\
gaps & $x$ & $x$ & $\checkmark$ & $\checkmark$ \\
\hline
\end{tabular}

Just like Gyeli PHG varieties, farmer languages show discontiguous categories, but much more so: black in Bulu (9), and black and orange in Mabi (8) are more dispersed than the white outlier in Bibira. As to the second line in (10), the effect of finding no majority answer for a certain hue is absent in Bulu, but found in Mabi. The lack of a majority answer in Mabi is even more distinct than in Gyeli where every hue received at least a third of equal answers. In Mabi, however, certain hues received totally mixed answers. They are represented by a greenish dot in (8) and are typically found in the blue and brown areas.

Loanwords are not used in Mabi, but in Bulu. Some Bulu speakers call newly innovated categories such as blue and purple by their French loanwords-while pointing out that these terms are not part of the Bulu language-or through some comparison to objects in the world, both being represented by a colored square with a question mark in (9). For instance, for blue, many Bulu speakers use the word for 'sky', yóp. These comparisons are, however, not conventionalized and thus not used systematically across speakers. Comparisons and loanwords rather present transitory strategies in dealing with non-conventionalized color categories. In contrast, Mabi speakers do not use comparisons and loanwords when dealing with unconventionalized areas, they lack majority answers.

Finally, both farmer languages have in common that, in contrast to the Gyeli PHGs, there are gaps in the color space. Gaps, represented by a question mark on a white background in the color space, occur when a majority of speakers declared 


\section{Nadine Grimm}

that they did not know any name for that particular hue in their language. Gaps occur in Mabi in the purple space and, in both Mabi and Bulu, in the brown space which has in neither language a term, i.e. the majority of speakers would neither use loanwords nor comparisons. Since none of the color terms they already have at hand can sufficiently describe the specific hue for which speakers seem to feel that they are not part of any other category, gaps may indicate that speakers are acquiring a new color category which is at an early stage of acquisition.

\section{Outlook}

The data from the the Gyeli PHG varieties and Bulu correspond, on the one hand, with the predictions of the Basic Color Term theory regarding the order in acquiring new color terms. Historically, these languages disposed of three color terms (red, black and white). Newly incoming colors follow the predicted order of yellow $\rightarrow$ green $\rightarrow$ blue $\rightarrow$ purple, orange, and brown. Mabi, however, contradicts these principles because orange becomes established before blue. On the other hand, the findings also support Levinson (2000)'s proposal that color categories and color terms emerge slowly and gradually under certain societal pressures. Bantu farmer languages acquire new colors under the influence of colonial color systems while Gyeli PHGs are adopting the recently and well established color categories yellow and green from the more prestigious Bantu farmer languages. The Gyeli and Bantu farmers cases show that either a lexical term or a color category can be borrowed without necessarily involving the borrowing of the two at the same time.

For future work, it would be valuable to track how the color systems of the four speech communities, and possibly other languages of the area, develop over time, for instance, to test whether new color categories of the Bantu farmers, once they are stably established, also trickle down into the Gyeli PHGs' language. Furthermore, since the present study is only concerned with color borrowing in a limited area, studies on color borrowing in other contact situations could shed light on whether one of the two presented paths of borrowing is more frequent than the other as well as whether a certain path of borrowing is constrained by certain factors.

\section{References}

Bahuchet, Serge. in prep. The linguistic diversity if the African rainforest Pygmy hunter-gatherers. In T. Güldemann, P. McConvell and R. Rhodes, eds., Huntergatherers and linguistic history: a global perspective. Cambridge: Cambridge University Press.

Bates, George L. 1904. Handbook of Bulu. London: Richard Clay and Sons.

Berlin, Brent and Paul Kay. 1999. Basic Color Terms: Their Universality and Evolution. CSLI Publications: Leland Stanford University.

Cook, Richard S., Paul Kay and Terry Regier. 2005. The World Color Survey database: History and use. In H. Cohen and C. Lefebvre, eds., Handbook of 


\section{Color Categories in Language Contact}

Categorization in Cognitive Science, 338-358. Amsterdam: Elsevier.

Joiris, Daou V. 2003. The framework of central African hunter-gatherers and neighboring societies. African Study Monographs Suppl. 28:57-79.

Kay, Paul et al. 1997. Color naming across languages. In C.L. Hardin and Luisa Maffi, eds., Color Categories in Thought and Language. Cambridge: Cambridge University Press.

Levinson, Stephen C. 2000. Yélî Dnye and the theory of basic color terms. Journal of Linguistic Anthropology 10(1):3-55.

Lewis, Jerome. 2002. Forest Hunter-Gatherers and their World: A Study of the Mbendjele Yaka Pygmies of Congo-Brazzaville and Their Secular and Religious Activities and Representations. PhD Thesis. Department of Social Anthropology: London School of Economics and Political Science.

Majid, Asifa and Stephen C. Levinson. 2007. The language of vision I: Colour. In Asifa Majid, ed., Field Manual 10:22-25. Nijmegen: Max Planck Institute for Psycholinguistics.

Roberson, Debi, Ian Davies and Jules Davidoff. 2000. Colour categories are not universal: Replications and new evidence from a Stone-age culture. Journal of Experimental Psychology: General 129:369-398.

Thomas, Jacqueline M. C. 1976. Classes et genres nominaux en aka, langue bantoue des pygmées de Mongomba (RCA). In L. Bouquiaux, ed., Théories et Methodes en Linguistique Africaines, 27-36. SELAF 54-55. Paris: SELAF.

UN Cartographic Section, Map of Cameroon, September 2004, No. 4227, available at: http://www.unhcr.org/refworld/docid/4607b9a62.html [accessed 7 May 2012]

Vorbichler, Anton. 1960. Die sprachlichen Beziehungen zwischen den Waldnegern und Pygmäen in der Republik Kongo-Léopoldville. In Actes du VIe Congrès International des Sciences Anthropologiques et Ethnologiques. Paris, 85-91.

Nadine Grimm

Humboldt University Berlin

Institute of Asian and African Studies

Invalidenstraße 118

10115 Berlin, Germany

nadinegrimm1@gmail.com 